\title{
VIRTUAL RESPIRATORY SYSTEM FOR INTERACTIVE E-LEARNING OF SPIROMETRY
}

\author{
W. Tomalak, T. Gólczewski, M. Michnikowski and M. Darowski
}

Allied Respiratory Professionals Congress Travel Grant, sponsored by Viasys Healthcare

Dept of Physiopathology of Respiratory System, Institute for Tuberculosis and Lung Diseases, Rabka Branch, Poland

WINNING ABSTRACT: Progress in computer simulation technology offers new possibilities for modern medicine. On one hand - virtual organs can help to create animal or human models for research, on the other hand - e-learning or distant learning through Internet is now possible. The aim of our work was to create a system for interactive learning of spirometry (SILS), enabling students or physicians to observe spirometric measurements (flow-volume) modified by setting level and kind of abnormalities within the respiratory system. SILS is based on a virtual respiratory system presented previously in several papers. Its main features are: separation of the lungs and chest; anatomical division of the lungs; division of airway resistance into transmural pressure dependent $(R p)$ and lung volume dependent $(R v)$ parts. The one mathematical formula that represents Rp describes both flow limitation (forced expiration) and dependence of Raw on lungs volume (small airflows). The output of system are spirometric parameters (as FEV1, FVC, FEV1\%FVC) and a flow-volume loop constructed according to results of simulation of forced expiration for the chosen abnormality kind and level.

As a result - this system may be used in teaching process in medical schools and postgraduate education. We offer access to a basic version of SILS for students and physicians at: www.spirometry.ibib.waw.pl and www.zpigichp.edu.pl. As we expect feedback from users, it is possible to modify user interface or model features to comply with users' requests.

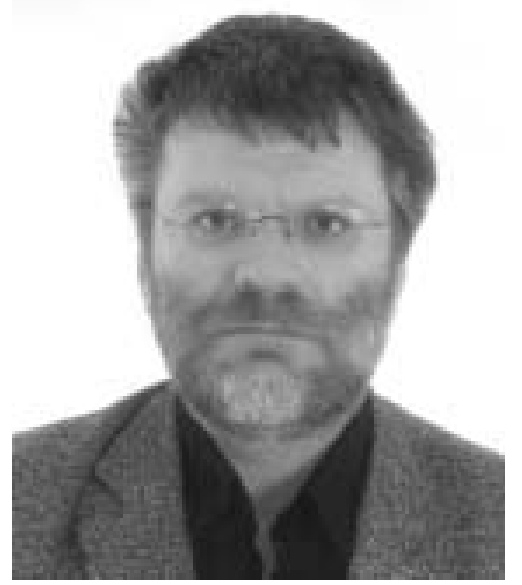

Waldemar Tomalak

Dept of Physiopathology of Respiratory System, Institute for Tuberculosis and Lung Diseases, Rabka Branch, Poland

\section{MY JOB AND THE UNIT IN WHICH I WORK}

I work in the Dept of Physiopathology of Respiratory System in a paediatric branch of the National Research Institute for Tuberculosis and Lung Diseases (Rabka Branch, Poland). I began my career as a research assistant and, since 1999, I have been head of the dept. The dept performs lung function testing in the patients from different clinics of the institute, and for children in the outpatient's dept. We cover the full range of tests, not only classical (i.e. spirometry, body plethysmography, diffusion tests), but also a range of tests specifically aimed

STATEMENT OF INTEREST: None declared. at children (i.e. forced oscillation technique, impulse oscillometry) or at special groups of patients (i.e. tests of respiratory muscles, assessment of expiratory flow limitation by negative expiratory pressure method, exhaled nitric oxide concentration). The staff within the dept are multidisciplinary and composed of a biomedical engineer, a computer sciences specialist, an electronic engineer and technicians prepared to cooperate with medical doctors.

My main research interests include lung function technology, methodology of the assessment of lung function [1, 2], normative values of different lung function indices in children $[3,4]$, the forced oscillation technique (including impulse oscillometry) [5], modelling of the respiratory system [6], quality of the measurements [7] and, more recently, sleeprelated breathing disorders (analysis of the data from polysomnographic measurements made in the dept). We collaborate with other research units in Poland and also in the UK (Newcastle-upon-Tyne, Dr J. Cotes [8, 9]) and Sweden (Goeteborg, Professor J. Hedner [10]).

\section{THE IMPACT OF MY WORK ON CLINICAL OR RESEARCH PRACTICE}

Virtual respiratory system for interactive e-learning of spirometry

Spirometry is the most common measuring technique used to assess respiratory system properties. Different pathophysiological phenomena are mirrored in the shape of the flow-volume curve and values obtained from it. Recent progress in computer tools has made it possible to use simulation programs in education.

Such programs allow hidden mathematical formulas describing different phenomena (flow limitation, wave speed limitation in the airways) behind the attractive user interface. When detailed models are used, a spirogram corresponding to real situations can be created. A grant from the Polish Ministry of 


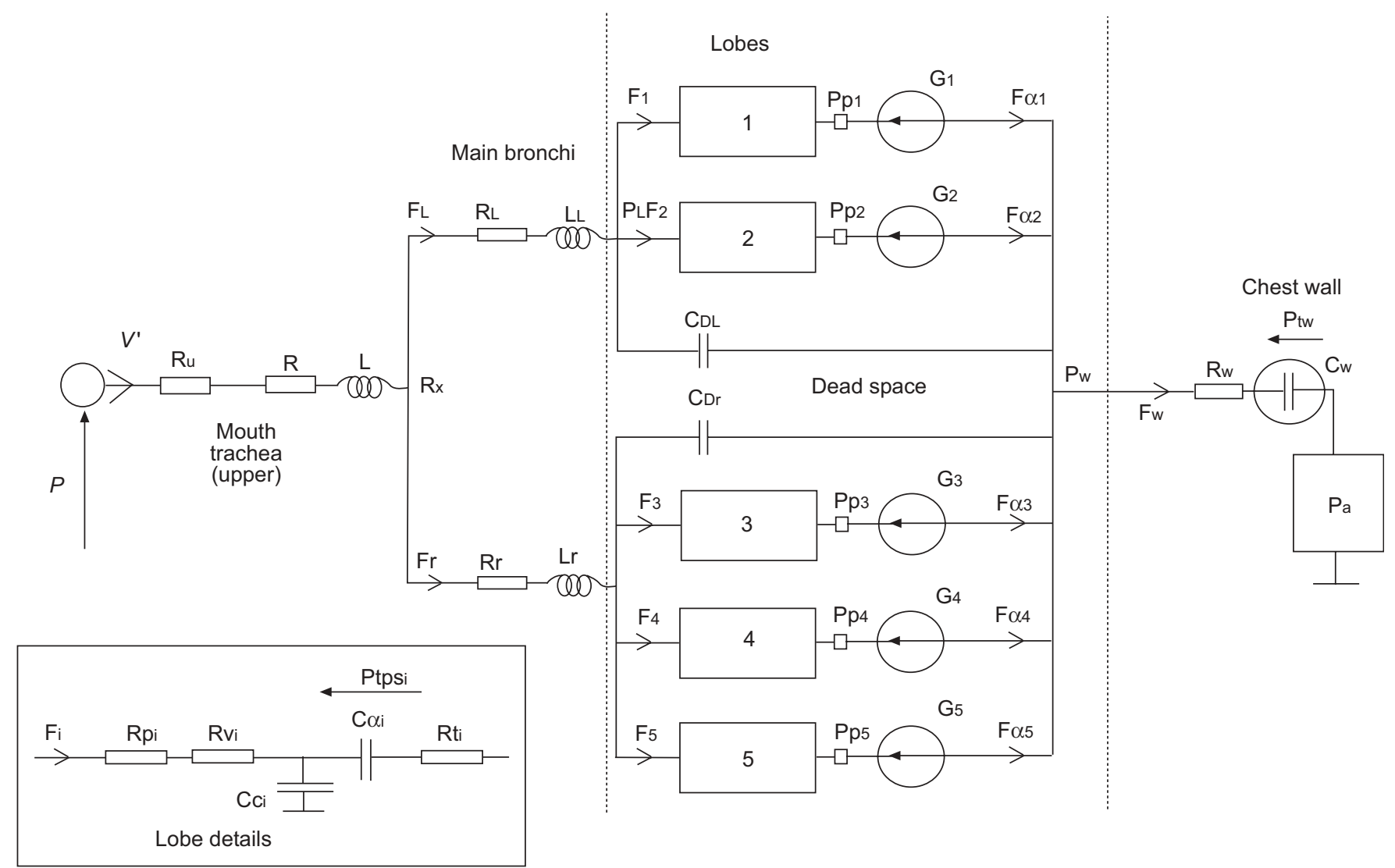

FIGURE 1. Respiratory system model used with the simulation programme. P: pressures at various points; V: volume; F: different flows; R: resistances; C: compliances or gas volumes; L: mass or gas inertances in the respiratory system. See the text for a full detailed description.

Science and Higher Education (contract number R1302202) has enabled the program to be developed. The procedure simulating forced expiration uses anatomical models of the respiratory system elaborated in the Institute of Biocybernetics and Biomedical Engineering in Warsaw (Poland), which have been verified previously [11]. It features the upper airway segment, five lobes and the chest wall (fig. 1).

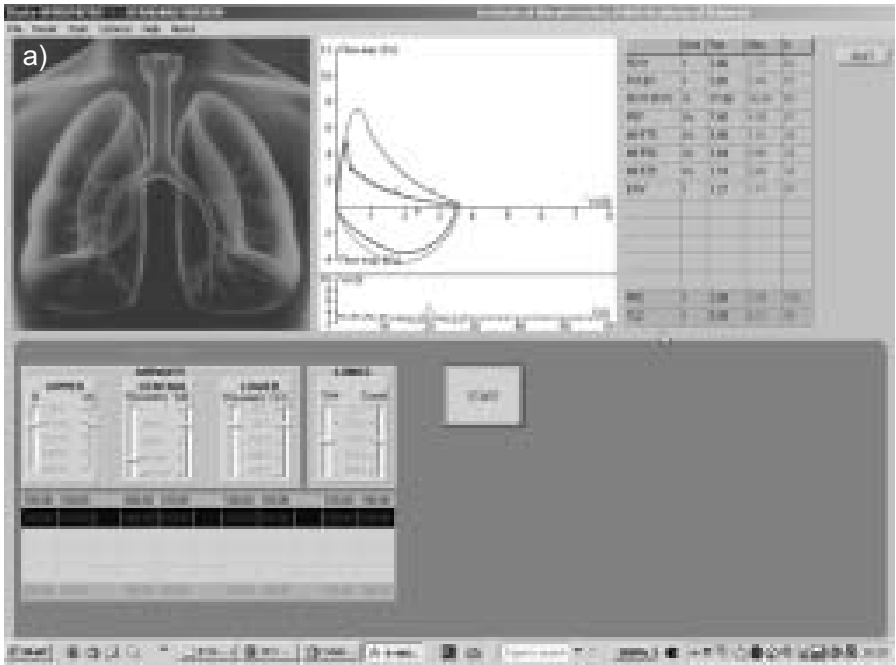

By changing the properties of a system, represented by resistances or compliances in the model, it is possible to produce changes in the shape of the flow-volume curve; for example, increasing the resistances of the main bronchi for both lungs simulates obstruction in the central airways (fig. 2). The program is designed in such a way as to allow modification of different properties (e.g. upper, central and

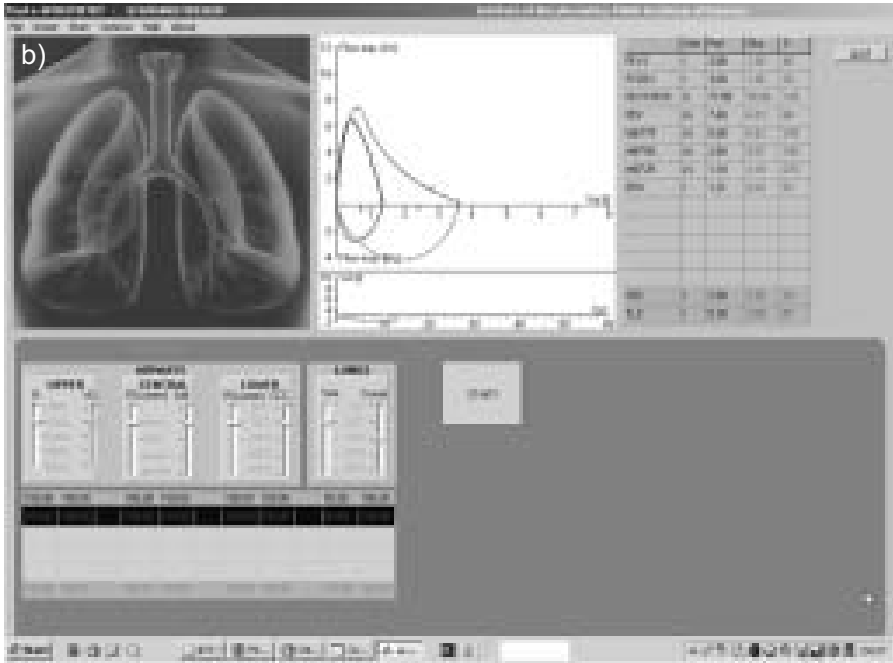

FIGURE 2. Image of a computer screen showing of a) increased central airway resistance or b) decreased lung volume. 
peripheral resistances, lung volume and stiffness, etc.). Moreover, the changes can be applied either to the whole system (global changes in all lobes) or in a limited manner, i.e. to one lobe, to observe a regional influence of increased resistance.

Such an approach makes it possible to test different situations. We believe that it represents the most attractive way of learning because of its interactivity. Moreover, it can be used in distance learning when the program is installed on a server and works in a network environment.

Finally, the question arises as to whether using such tools in education will enhance the efficiency of learning. We will undertake an attempt to assess the efficiency of using the program in postgraduate education.

\section{REFERENCES}

1 Pawlik J, Tomalak W, Radliński J, Myszkal W. Methodological aspects of the measurement of exhaled NO level. Eur Respir J 2006; 28: Suppl. 50, 727s.

2 Latawiec W, Tomalak W, Radliński J, Pawlik J. Quantitative analysis of the influence of "supporting the cheeks" on input impedance and upper airways impedance measurements. Eur Respir J 2006; 28: Suppl. 50, 421s-422s.

3 Tomalak W, Pogorzelski A, Prusak J. Normal values for maximal static expiratory and inspiratory pressures in healthy children. Pediatr Pulmonol 2002; 34: 42-46.
4 Tomalak W, Radliński J, Pogorzelski A, Doniec Z. Reference values for forced inspiratory flow in children aged 7-15 years. Pediatr Pulmonol 2004; 38: 246-249.

5 Tomalak W, Radliński J, Pawlik J, Latawiec W, Pogorzelski A. Impulse oscillometry vs body plethysmography in assessing respiratory resistance in children. Pediatr Pulmonol 2006; 41: 50-54.

6 Tomalak W, Radliński J, Pawlik J, Latawiec W, Myszkal W. Correlation of IOS-oscillometric model parameters (central and peripheral resistances) to spirometric indices in children. Eur Respir J 2005; 26: Suppl. 49, 119s.

7 Tomalak W, Radlinski J, Myszkal B. Performance of spirometry in children aged 10 years and less. Eur Respir J 2007; 30: Suppl. 51, 89s.

8 Tomalak W, Cotes J. Does gender influence tidal volume and respiratory frequency during exercise? Eur Respir J 2002; 20: Suppl. 38, 489s.

9 Cotes J, Tomalak W, Radlinski J. Pattern of breathing (frequency and tidal volume) influences level and interpretation of exercise ventilation in childhood. Eur Respir J 2007; 30: Suppl. 51, 324s.

10 Grote L, Zou D, Radlinski J, Eder D, Hedner J. Nocturnal heart rate entropy is related to daytime blood pressure. Eur Respir J 2007; 30: Suppl. 51, 508-509s.

11 Golczewski T, Darowski M. Virtual respiratory system for education and research: simulation of expiratory flow limitation for spirometry. Int J Artif Organs 2006; 29: 961-972. 